\title{
BMJ Open Fetal alcohol spectrum disorders from childhood to adulthood: a Swedish population-based naturalistic cohort study of adoptees from Eastern Europe
}

\author{
Valdemar Landgren (D) , , ${ }^{1,2}$ Leif Svensson, ${ }^{3}$ Emelie Gyllencreutz, ${ }^{4,5}$ Eva Aring, ${ }^{5,6}$ \\ Marita Andersson Grönlund, ${ }^{5,6}$ Magnus Landgren ${ }^{2,3}$
}

To cite: Landgren V, Svensson L, Gyllencreutz E, et al. Fetal alcohol spectrum disorders from childhood to adulthood: a Swedish population-based naturalistic cohort study of adoptees from Eastern Europe. BMJ Open 2019;9:e032407. doi:10.1136/ bmjopen-2019-032407

- Prepublication history and additional material for this paper are available online. To view these files, please visit the journal online (http://dx.doi org/10.1136/bmjopen-2019032407).

Received 17 June 2019 Revised 21 August 2019 Accepted 11 October 2019

Check for updates

(C) Author(s) (or their employer(s)) 2019. Re-use permitted under CC BY-NC. No commercial re-use. See rights and permissions. Published by BMJ.

For numbered affiliations see end of article.

Correspondence to Dr Valdemar Landgren; valdemar.landgren@gu.se

\section{ABSTRACT}

Background Fetal alcohol spectrum disorders (FASD) are a global health concern. To further understand FASD in adulthood is a major public health interest.

Objective To describe the clinical characteristics of young adults with FASD adopted from orphanages to a socially more favourable and stable rearing environment as children.

Design Prospective observational cohort study Setting Western Sweden

Participants A population-based cohort of 37 adoptees diagnosed with FASD in childhood.

Outcome measures Assessment consisted of clinical evaluations of social, medical, psychiatric, neuropsychological, adaptive and ophthalmological status by a physician, ophthalmologist, orthoptist and psychologist.

Results Out of 37 adoptees with FASD, 36 (15 females) were evaluated at a median age of 22 years (range 18-28) and a mean follow-up time of 15.5 years (range 13-17). Twenty (56\%) were dependent on social support. Sexual victimisation was reported by nine (26\%). In 21 individuals with fetal alcohol syndrome, growth restriction in height and head circumference of approximately -1.8 SD persisted into adulthood. Of 32 examined, 22 (69\%) had gross motor coordination abnormalities. High blood pressure was measured in nine (28\%). Ophthalmological abnormalities were found in 29 of $30(97 \%)$. A median IQ of 86 in childhood had declined significantly to 71 by adulthood (mean difference: $15.5 ; 95 \% \mathrm{Cl} 9.5-21.4$ ). Psychiatric disorders were diagnosed in $88 \%$, most commonly attention deficit hyperactivity disorder $(70 \%)$. Three or more disorders were diagnosed in $48 \%$, and $21 \%$ had attempted suicide. The median Clinical Global Impression-Severity score was $6=$ 'severely ill'.

Conclusion Major cognitive impairments, psychiatric morbidity, facial dysmorphology, growth restriction and ophthalmological abnormalities accompanies FASD in adulthood. Recognition of FASD in childhood warrants habilitation across the lifespan.

\section{INTRODUCTION}

The link between prenatal alcohol exposure and brain injury has been known to exist for centuries. ${ }^{1}$ With the independent
Strengths and limitations of this study

- A population-based cohort of adoptees with fetal alcohol spectrum disorders (FASD), avoiding clinicalbased bias.

- Face-to-face clinical evaluations by the same assessors in childhood as adulthood.

- Small sample size decreases the precision of results and their generalisability.

- No particular comparison group of adoptees without FASD.

- A clear separation of innate effects of alcohol exposure and postnatal deprivation not possible, although adoption infers an optimisation of the environment compared with orphanage.

recognition of alcohol-related malformations, by Lemoine, Ulleland, Smith, Jones and colleagues, a clinical syndrome was identified which eventually became known as fetal alcohol syndrome (FAS). ${ }^{23}$ Since then, major contributions in epidemiological and teratological research have corroborated the deleterious effects of alcohol exposure during pregnancy, elucidating the pathogenic mechanisms of alcohol on the face and brain in particular. ${ }^{45}$ A spectrum of alcohol effects on embryonic and fetal development has been recognised, and is today known as fetal alcohol spectrum disorders (FASD). Diagnostic criteria differ somewhat between countries, but the key features of FAS-growth deficiency, facial dysmorphology and neurobehavioral impairment-remain the same as originally described. ${ }^{6}$ The clinical criteria for FASD, according to Hoyme $e t a l,{ }^{57}$ recognise that individuals with all key features have FAS, whereas those with facial dysmorphology and neurobehavioral impairment are recognised as having partial FAS (PFAS), and those with confirmed alcohol exposure and neurobehavioral impairment as having alcohol-related 
neurodevelopmental disorder (ARND). Finally, concurrent facial dysmorphology and structural birth defects are diagnosed as alcohol-related birth defect (ARBD).

Although epidemiological studies and estimates of FASD consistently report minimum prevalence rates of $1.1 \%-5 \%,{ }^{8-12}$ the contribution from alcohol exposure during pregnancy to the global economic and health burden is frequently overlooked ${ }^{1314}$ and is deemed grossly underestimated. ${ }^{15}$

The literature on the consequences of FASD in adulthood is limited, but there are indications of persistence of disabilities and need for long-term support. ${ }^{16}$ However, to distinguish the effects of prenatal alcohol exposure from those of an adverse postnatal rearing environment has been a methodological challenge, since children with FASD are at increased risk of unstable family relations and placements, orphanages, and adoptions. ${ }^{17-19}$ For children separated from their family, evidence suggests that adoption is associated with higher levels of emotional security and general well-being than provided by impermanent placements or orphanages, and therefore poses the best long-term alternative. ${ }^{2021}$

\section{Aims of the study}

The aim was to characterise young adult outcome of FASD in a socially favourable rearing environment, and to evaluate the diagnostic stability of FASD into adulthood.

\section{MATERIAL AND METHODS \\ Design, setting and participants}

In a previous population-based study all children adopted to western Sweden during 1990-1995 from Russia, Poland, Romania, Latvia or Estonia were invited for in-depth health examinations. Of 99 children invited, data on 76 children on arrival at a mean age 2.8 years was reported. ${ }^{22}$ At age 5-10 years, we diagnosed neurodevelopmental disorders in 64 of 71 children $(90 \%)^{23}$ and ocular abnormalities in 56 of $72(78 \%) .{ }^{24}{ }^{25}$ For $37(52 \%)$, a FASD diagnosis according to the criteria described by Hoyme $e t$ $a l^{7}$ with ascertained alcohol exposure, was confirmed in childhood. ${ }^{23}$ It has since been recognised that a frequent reason for leaving a child in an orphanage in this region includes maternal alcohol abuse. ${ }^{26}$ Because of insufficient data about many parents, exposure and birth status, 52\% likely reflected a minimum rate of FASD in our cohort. We thought this information bias made comparisons to those in the cohort without FASD invalid. Therefore, only the 37 individuals with diagnosed FASD were invited for follow-up visits in young adulthood (18-28 years).

\section{Assessment at adult follow-up}

Assessment consisted of evaluations of the participants' social, medical, psychiatric, ophthalmological and psychological status by a paediatric neurologist or resident physician, ophthalmologist, orthoptist and psychologist on up to three occasions. Half of the cohort was seen in 2014, the other half in 2017-2018.

\section{Social evaluation}

A structured questionnaire covering educational attainment and current social circumstances was used, generally administered to parents by phone, and clarified at the medical examination.

\section{Medical evaluation}

Lung and heart auscultation, neurological examination of reflexes, muscle tone, finger to nose test and heel to shin test, and diadochokinesis test were performed by the examining physician. Measurements of height, weight, body mass index (BMI), occipitofrontal circumference (OFC) and blood pressure (BP) were recorded and converted to appropriate SDs and percentile scores. $\mathrm{BP}$ and heart rate were recorded according to instructions by the US National High Blood Pressure Education Program. ${ }^{27}$ Upper lip and philtrum were assessed independently and were scored using the Lip-Philtrum Guide ${ }^{57}$ Lip and philtrum rating at the first assessment was done with a scale that preceded the one currently in use. $^{28}$ To enable comparison of diagnostic domains of FASD in childhood and at follow-up in adulthood, frontal photos of the participants taken at first assessment were rated using the Hoyme et al s Lip-Philtrum Guide (2016). Pain or sleep problems were present if a significant disturbance was reported at least once a week.

\section{Psychiatric evaluation}

To assess for affective psychotic disorders, substance abuse and antisocial personality disorder, the Mini International Neuropsychiatric Interview 6.0.0 (MINI) ${ }^{29}$ was used by the examining physician. Presence of attention deficit hyperactivity disorder (ADHD) was assessed with questions from the Adult ADHD Self-Report scale 1.1. ${ }^{30}$ Because young adults tend to underestimate ADHD symptoms, ${ }^{31}$ the assessment was informed by family, the medical records, other measures when available and clinical judgement. Based on all available information, the clinical condition was evaluated with the Clinical Global Impression-severity (CGI-S) instrument, using an ordinal scale where $1=$ 'normal' and $7=$ 'extremely ill'. ${ }^{32}$ The scoring rationale for the CGI-S and clinical vignettes exemplifying each score can be found in the online supplementary file.

\section{Ophthalmological evaluation}

An ophthalmological assessment of visual acuity, refraction, strabismus and structural abnormalities was made by ophthalmologist and orthoptist, with the same procedure as in the original study. ${ }^{23}$ An in-depth report of the ophthalmological assessment will be published elsewhere.

\section{Psychological evaluation}

Leiter-Revised (Leiter-R) non-verbal tests, ${ }^{33}$ consisting of an IQ test of fluid reasoning and visualisation, as well as the Leiter-R Attention and Memory battery, were administered. The Leiter-R rating scales for parents and psychologists, and the Adaptive Behavior Assessment Scale (ABAS-II) parent form $^{34}$ were also administered. The 


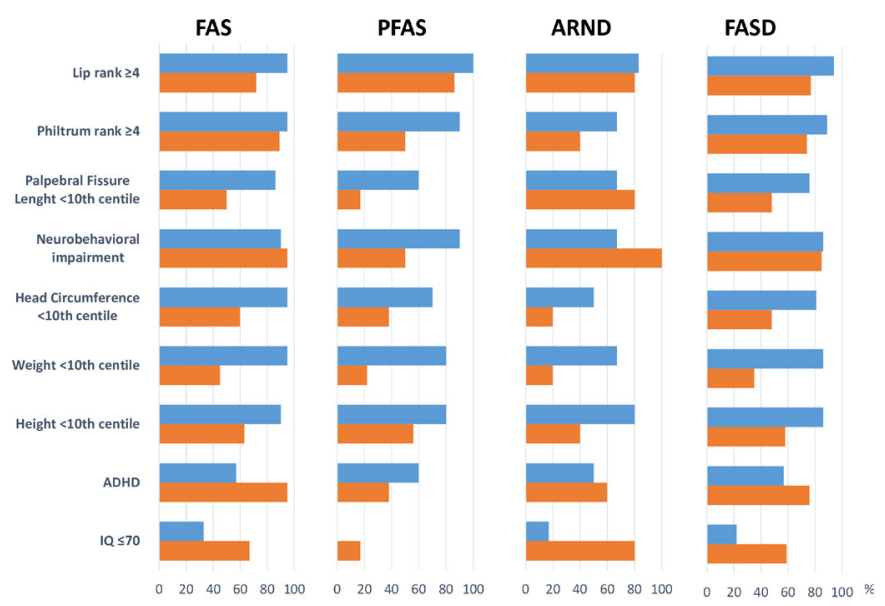

Childhood Adulthood

Figure 1 Diagnostic domains of fetal alcohol spectrum disorders in childhood and young adulthood in 37 adoptees.

testing was conducted by the same psychologist (LS) as in the original study. ${ }^{23}$

\section{Patient and public involvement}

Patients were not directly involved in the design, recruitment or in the conduct of this study.

\section{Statistical methods}

SPSS V.22 (IBM Corp.) was used for all analyses. Frequencies, means, SDs, medians and ranges were calculated for descriptive purposes. When comparing continuous data being reassessed, paired samples test was performed. For detection of subgroup differences, Kruskal-Wallis test was used.

\begin{tabular}{|c|c|}
\hline & $(n=36)$ \\
\hline \multicolumn{2}{|l|}{ Highest completed education } \\
\hline Special education & $14(39)$ \\
\hline Primary school, 9 years & $9(25)$ \\
\hline Secondary school, 12 years & $11(31)$ \\
\hline Attempted university studies & $2(5)$ \\
\hline \multicolumn{2}{|l|}{ Criminality } \\
\hline Victim of sexual crime* & $9(26)$ \\
\hline Victim of physical assault & $4(12)$ \\
\hline Criminal convictions $†$ & $2(6)$ \\
\hline \multicolumn{2}{|l|}{ Income and compensation } \\
\hline Working & $11(31)$ \\
\hline Social welfare & $10(28)$ \\
\hline Disability pension & $10(28)$ \\
\hline Student & $5(14)$ \\
\hline
\end{tabular}

Values expressed as numbers and percentages.

${ }^{*}$ Reported by six women and three men.

†Two men reported convictions for drug-related theft and violence.

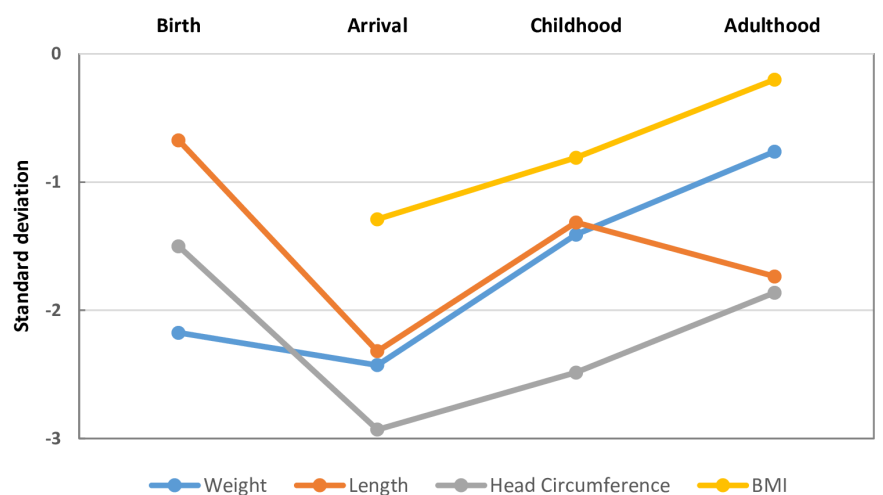

Figure 2 Anthropometric measurements at four time points for 21 adoptees with fetal alcohol syndrome

\section{RESULTS}

The follow-up cohort consisted of 36 of 37 individuals $(97 \%), 15$ females, with a median age of 22 years (range 18-28 years) and a median follow-up time of 15.5 years (range 13-17 years). Half of the group seen in 2014 were mainly individuals with a FAS diagnosis. The social interview was completed by 36 individuals, the medical and psychiatric examination by 32 , the ophthalmological by 30 and the psychological examination by 29. Medical charts contributed additional data for some individuals. Morbidity, reluctance towards further investigations, and the inconveniences of travelling were reasons for participation in only some of the tests.

\section{Social evaluation}

The participants' social circumstances are shown in table 1 .

\section{Medical evaluation}

Measurements and traits within the diagnostic domains of FASD at the time of diagnosis and at follow-up are summarised in figure 1. Mean SDs of weight, length, head circumference and BMI at four measurements for the FAS group are depicted in figure 2. Symptoms, findings and health measures reported at the medical assessment are presented in table 2.

\section{Psychiatric evaluation}

Results of the psychiatric interviews are summarised in table 3 .

Substance use disorders were found in two cases each of polysubstance use and alcohol use. A formalised evaluation of autistic traits was not part of the assessment, but four individuals reported having been diagnosed with autism outside the study. Past and/or present contact with adult psychiatry was reported by 18 individuals $(50 \%)$. Participants with FAS had higher CGI-S scores, but in post-hoc analyses no significant differences between the FASD subgroups were found (Kruskal-Wallis test; $\mathrm{p}=0.07$ ). Clinical vignettes with CGI-S scores are found in online supplementary appendix S1. 
Table 2 Medical examination of adoptees with fetal alcohol spectrum disorders in young adulthood

\begin{tabular}{lc}
\hline & (n=32) \\
\hline Any abnormal motor finding & $22(69)$ \\
\hline Dysdiadochokinesis & $15(47)$ \\
\hline Balance disturbance & $5(16)$ \\
\hline Abnormal muscle tone & $4(13)$ \\
\hline Ataxia & $2(6)$ \\
Abducens paresis & $1(3)$ \\
Any somatic complaint & $24(75)$ \\
\hline Sleep disturbance & $15(41)$ \\
\hline Headache & $11(30)$ \\
\hline Other pain & $10(27)$ \\
Stomach disturbance & $6(16)$ \\
\hline Any metabolic risk factor & $(\mathrm{n}=35)^{\star}$ \\
\hline Body mass index $\geq 25$ & $18(51)$ \\
\hline Tobacco smoker & $10(30)$ \\
\hline Hypertensive† & $7(20)$ \\
Prehypertensive & $9(28)$ \\
Any psychotropic medication & $3(9)$ \\
\hline ADHD medication & $16(46)$ \\
\hline Antidepressants & $8(23)$ \\
\hline Neuroleptic & $7(20)$ \\
\hline Anticonvulsant & $3(9)$ \\
\hline & $3(9)$ \\
\hline & $3(9)$ \\
\hline Asthma treatment & \\
\hline
\end{tabular}

Values expressed as numbers and percentages.

*Information was obtained via telephone and from the medical records in three additional cases.

†Three individuals were concurrently receiving attention deficit hyperactivity disorder (ADHD) medication.

\section{Ophthalmological evaluation}

Measurements of inner canthal distance (ICD) and palpebral fissure length (PFL) are given in online supplementary table S1. In the cohort, findings of ophthalmological abnormalities, such as low visual acuity, refractive errors, strabismus, ptosis and intraocular abnormalities (increased tortuosity of retinal vessels, abnormal optic disc), were seen in 32 out of $37(86 \%)$ in childhood $^{24}$ and in 29 out of $30(97 \%)$ at follow-up.

\section{Psychological evaluation}

Scores for the Leiter-R IQ and ABAS-II are shown in online supplementary table S2. Increased deficits in adaptive and cognitive functions in relation to the expected trajectory were noted by the psychologist. In a post-hoc analysis of the baseline median IQ score of 86 , the median IQ at follow-up was significantly lower, 71 (paired samples test mean difference: $15.4 ; 95 \%$ CI 9.5 to 21.4). When comparing only individuals with data at both time points (childhood and adulthood, $n=29$ ), the difference
Table 3 Psychiatric assessment of adoptees with fetal alcohol spectrum disorders in childhood and young adulthood

\begin{tabular}{|c|c|}
\hline DSM-IV diagnosis & \\
\hline Childhood* $^{*}$ & $(n=37)$ \\
\hline Any disorder & $30(81)$ \\
\hline Attention deficit hyperactivity disorder & $23(62)$ \\
\hline Oppositional defiant disorder & $16(43)$ \\
\hline Developmental coordination disorder & $15(41)$ \\
\hline Tic disorder & $5(14)$ \\
\hline Autism & $2(5)$ \\
\hline Conduct disorder & $2(5)$ \\
\hline Obsessive compulsive disorder & $1(3)$ \\
\hline Adulthood $\dagger$ & $(n=33)$ \\
\hline Any disorder & $29(88)$ \\
\hline Attention deficit hyperactivity disorder & $23(70)$ \\
\hline Any anxiety disorder & $17(52)$ \\
\hline Social phobia & $8(24)$ \\
\hline Panic disorder & $7(21)$ \\
\hline Generalised anxiety disorder & $7(21)$ \\
\hline Agoraphobia & $5(15)$ \\
\hline Three or more disorders $\ddagger$ & $16(48)$ \\
\hline Any depressive episode & $14(42)$ \\
\hline Self-injurious behaviour & $8(24)$ \\
\hline Suicide attempt & $7(21)$ \\
\hline Autism & $4(12)$ \\
\hline Substance use disorder & $4(12)$ \\
\hline Manic or hypomanic episode & $3(9)$ \\
\hline Antisocial personality disorder & $2(6)$ \\
\hline Obsessive compulsive disorder & $2(6)$ \\
\hline Eating disorder & $2(6)$ \\
\hline Psychotic disorder & $1(3)$ \\
\hline \multicolumn{2}{|l|}{ CGI-S score§ } \\
\hline $1=$ normal & $2(6)$ \\
\hline 2-3=borderline to mildly ill & $5(15)$ \\
\hline $4-5=$ moderately to markedly ill & $6(18)$ \\
\hline $6-7=$ severely to extremely ill & $21(62)$ \\
\hline
\end{tabular}

Data are presented as numbers (and percentages).

${ }^{*}$ Childhood diagnosis was based on evaluation by a paediatrician, psychologist and ophthalmologist.

tThe diagnostic rationale is described under 'Methods'.

\#ln the composite measure of 'three or more disorders', multiple anxiety disorders in the same individual are considered as one. Suicide attempt and self-injurious behaviour are not included.

$\S$ See (online supplementary appendix S1) for the scoring rationale and clinical vignettes.

CGI-S, Clinical Global Impression -Severity; DSM-IV, Diagnostic and Statistical Manual of Mental Disorders, 4th edition.

remained significant (paired samples test mean difference $18.9 ; 95 \%$ CI 12.7 to 25.0 ).

\section{DISCUSSION}

This observational, population-based cohort study provides insight into the long-term outcomes in young 
adulthood of children with FASD raised in a socially favourable environment. In summary, the proportion still meeting diagnostic criteria for FASD in adulthood was substantial, and participants exhibited high rates of social dependency, medical, psychiatric, ophthalmological symptoms and cognitive impairments.

Results must be interpreted with caution due to limitations. Sample size is small, and there was no specific comparison group from study initiation. Two time points for follow-up introduced a systematic bias of younger age in those with FAS, although all were 18 years or older. Educational attainment and health trajectory compared with that of older participants is therefore uncertain, and in all participants follow-up time is limited to young adulthood. However, results may be juxtaposed to the few studies of adults prenatally exposed to alcohol, raised in chaotic family situations or in institutional care. This allows for some inference about the role of environment. ${ }^{1735} 36$ Individuals with FASD has been underrecognised and overrepresented among children in out-of-home placements. ${ }^{18} 1936$ Therefore we think the findings from this study has external validity when applied to individuals in out-of-home placement for similar reasons, that is, maternal drug abuse, and that country of origin or age at adoption, are of subordinate importance. Because alcohol exposure is rarely assessed biochemically or with adequate interview techniques, ${ }^{5} 37$ it is often underestimated and may confound comparisons with other cohorts.

The proportion of participants with FASD graduating from secondary school after 12 years of education (36\%) in this cohort is substantially lower than that reported for earlier groups of Swedish adoptees, adopted due to national crises of war, rather than drug abuse (Of 8000 individuals adopted from Asian countries to Sweden during the 1970s, graduation was achieved in slightly lower rates $(80 \%)$ compared with Swedish-born peers $(85 \%)) .{ }^{38}$ At an age of around 40 years, $11 \%$ of Asian adoptees were dependent predominately on social support, in comparison with $5 \%$ of the general population, ${ }^{38}$ which is substantially lower than the $56 \%$ reported for this younger cohort. This rate is in line with a Swedish registry-based follow-up of 72 individuals with FASD, with a $51 \%$ unemployment rate at a mean age of 32 years. ${ }^{36}$ The differences suggest innate, rather than social, factors as determinants of social prognosis. Streissguth, studying a clinical sample of 90 young adults with FASD, ${ }^{39}$ estimated a $60 \%$ lifetime prevalence of delinquency, which is in contrast to the prevalence of $6 \%$ found in this study. We hypothesise that the transition to a relatively stable social environment of adoption outside of big cities mitigates this risk.

When diagnostic criteria are revisited in adulthood, the proportion fulfilling the anthropometric criteria are somewhat decreased. The philtrum and lip rank is still high, but this criterion must be interpreted with caution as it may suffer from observer bias, and absence of validated scales for dysmorphological evaluation of FASD in adults. This highlights the difficulty of diagnosing FASD in adulthood, and the need for complementary diagnostic methods.

The anthropometric measurements of the FAS group were below the population mean at all time points. The markedly small head circumference and stunted height, noted on arrival in Sweden, probably represents a consequence of prenatal suboptimality in general and alcohol exposure in particular, followed by an unfavourable rearing environment. ${ }^{22}$ The arrival to a more favourable milieu as these children were adopted resulted in a partial correction of the stunted growth patterns towards normal ranges. BMI steadily increased from arrival to adulthood and can be expected to continue with increasing age, in line with secular trends. ${ }^{40}$ However, the patterns of stunted growth figures of $-2 \mathrm{SD}$ for height and head circumference returned in adulthood, and implies an altered trajectory of growth in FAS. Stunted growth patterns in children when encountered clinically should not be evaluated only medically in a strict sense, but also using thorough multidisciplinary neurodevelopmental examinations longitudinally. ${ }^{41}$ A fragmented healthcare where so termed psychiatric, social or medical symptoms are assessed as isolated phenomena, otherwise struggles to detect intricate biopsychosocial patterns as exemplified by FASD.

High BP was found in nine (28\%) individuals. Unfortunately, repeat measurements were not possible. The expected prevalence of hypertension at this age in this setting is $2 \% .{ }^{42}$ In conjunction with elevated rates of smoking and increasing BMI, the high rate in our cohort may signal an impending health concern. The Barker hypothesis states that ailments of adulthood, such as cardiovascular disease and metabolic syndrome, have fetal origins. ${ }^{43}$ Studies of preterm birth and low birth weight support this hypothesis. ${ }^{44}$ Alcohol exposure, being related to both preterm birth and low birth weight, may therefore be an underestimated factor for fetal origins of disease, and warrants further longitudinal study. ${ }^{45}$

The lifetime prevalence of epilepsy increased from one $(3 \%)$ in childhood to three $(8 \%)$ in young adulthood. Epilepsy was added to the 2016 revised criteria for FASD. ${ }^{5}$ Incidence of epilepsy is known to have a second peak in adolescence, ${ }^{46}$ and additional studies on adults may increase estimates of lifetime prevalence of epilepsy in FASD.

Motor abnormalities were found at similar rates in adulthood $(69 \%)$ as in childhood $(68 \%)$. This is in line with a study by Connor et al, where coordination problems persisted into adulthood for a clinical sample of 60 individuals with FASD. ${ }^{47} \mathrm{~A}$ few studies indicate persisting dysdiadochokinesis predictive of psychiatric morbidity in adulthood, such as schizophrenia and anorexia nervosa. ${ }^{48} 49$ The findings agree with the literature on soft motor signs being overrepresented among individuals with psychiatric morbidity, of whom individuals with FASD may constitute a substantial minority, given that $50 \%$ already reported contact with adult 
psychiatry. A relation between alcohol exposure and decreased basal ganglia volume has been described. ${ }^{50}$ Basal ganglia have been implicated in developmental coordination disorder (DCD) and learning disabilities, as well as ADHD ${ }^{51}$ Despite early reports of DCD in FAS, ${ }^{52}$ domains of coordination are not incorporated into diagnostic criteria. The persisting motor impairments and associated cognitive deficits caused by prenatally acquired brain injury that constitutes FASD suggest that FASD could be included under the umbrella term of cerebral palsy. ${ }^{53}$

The proportion exhibiting small palpebral fissures had decreased considerably by adulthood $(76 \%$ vs $47 \%$ ). Asymmetry, as captured by a difference in ICD and PFL $\geq 5 \mathrm{~mm}$, was likewise somewhat decreased $(46 \%$ vs $35 \%)$. Clinical presentations with asymmetrical growth pattern can raise concerns about FASD in addition to other genetic syndromes. ${ }^{54}$ Although the correlation between OFC and PFL has been assumed to be strong, ${ }^{55}$ the variance in PFL, explained by OFC where studied, is at best $15 \% \cdot{ }^{56}$ Whereas brain growth drives the growth of the head, PFL is better understood as related to factors other than crude brain size, such as growth of the eye $e^{56}$ and the forebrain. ${ }^{57}$ The correlation between ICD and PFL in patients with FASD has been weak, ${ }^{55}$ and ICD may therefore capture aspects of neurodevelopment not captured by PFL.

Non-specific somatic complaints have previously been reported in association with, and preceding, affective disorders ${ }^{58}$ both of which were common in this cohort. The heritability of affective disorders has been estimated to be $40 \% .^{59}$ Given that alcohol abuse sometimes indicates self-medication ${ }^{60}$ a genetic liability may be overrepresented in FASD independently of the alcohol exposure itself. In addition, traumatic experiences in childhood, academic and professional failure, and underachievement relative to peers pose an environmental substrate for demoralisation and chronic stress, increasing liability for affective disorders. ${ }^{59}$

The rates of depression, anxiety disorders and suicide attempts found in this cohort correspond to findings of earlier studies. ${ }^{35} 3961$ Executive dysfunction and marked attention problems have been highlighted elsewhere ${ }^{1735}$ but this is, to our knowledge, the first study in adults with FASD assessing criteria for ADHD. The increase in ADHD from childhood (62\%) to adulthood $(70 \%)$ may reflect both parents' tolerance for executive dysfunction in childhood and increased demands on executive function in adulthood. However, lower symptoms of impulsivity and less deviant social interactions in adulthood, based on standardised testing, could lead researchers to overestimate the functioning of adults with FASD, a point reiterated by researchers in the field of FASD. ${ }^{1762}$

In this cohort, psychotic disorders were rare (3\%), which is in contrast to results by Famy et al, ${ }^{63}$ who report mainly brief psychotic disorder, in $40 \%$ of 25 studied individuals with FASD. The relation between psychotic disorders and substance dependence in that sample is not discussed. The rate of depression (44\% vs $42 \%)$ and psychiatric disorders in general (92\% vs $88 \%$ ) was similar.

Mukherjee $e t a l^{64}$ compared children with FASD exposed $(n=45)$ and not exposed $(n=52)$ to prolonged neglect, and found no significant difference in neurodevelopmental morbidity. They concluded from their sample that alcohol exposure and innate factors explain neurodevelopmental morbidity alone, independently of neglect. This is in line with a recent twin study, where monozygotic twins, despite being differentially exposed to childhood maltreatment, were concordant regarding symptom rates of neurodevelopmental disorders. ${ }^{65}$ In a longitudinal study of English and Romanian adoptees, by Sonuga-Barke et al, two cohorts who spent $>6$ months versus $<6$ months in an institution were compared. Rates of emotional distress $(45 \%$ vs $18 \%$ ) and ADHD symptoms (32\% vs $12 \%$ ) were higher in the group with prolonged institutionalisation. ${ }^{66}$ Despite higher rates of extremely low birth weight $<2500 \mathrm{~g}$ (32.9\% vs $22 \%$ ) in the group with the prolonged stay, and limited reports of perinatal risks such as gestational age, alcohol exposure, birth head circumference or any dysmorphology assessment during the study, the difference in neurodevelopmental outcome was attributed mainly to institutional deprivation. It is worth noting that $30 \%$ of the initial cohort in our study were adoptees from Romania, ${ }^{22}$ born in the same years as the participants in Sonuga-Barke et $a l \mathrm{~s}$ cohort' but generally adopted at a later age (mean age 3.3 years). Given the high minimum rate of confirmed alcohol exposure in our initial sample (52\%) and the fact that institutions prioritise healthier children for internal adoptions at a young age, a bias towards higher rates of alcohol exposure may be a substantial source of confounding in their group of adoptees. ${ }^{66}$

A review by Kable et al summarises the literature on neurobehavioral deficits in FASD, specifically deficits in neurocognition, self-regulation and adaptive behaviour. ${ }^{62}$ A characteristic of FASD is increasing adaptive deficits with age, relative to peers. A higher than expected rate of autism has been reported previously in FASD ${ }^{6768}$ and deficits in social skills and communication are part of the adaptive deficits described. Adult adaptive functioning requires goaldirected behaviour, abstract thinking, generalisation of cause and effect, managing household, finances and social relations-all functions that are inseparable from neurocognition and self-regulation. The decrease in non-verbal IQ to adulthood indicates that stunted growth in FASD applies not only to weight and length but also to brain maturation and function, and corresponds to the adaptive deficits. To our knowledge, this marked decrease in IQ has not previously been demonstrated in the literature on FASD. The non-verbal tests cover spatial reasoning, working memory, problem solving, logical reasoning and generalisation, higher order functions requiring efficient interconnectivity of large brain areas. ${ }^{69}$ An underlying deficit in these higher order brain functions would be expected to affect proficiency in complex tasks in general, not just one, becoming more evident with age. 


\section{CONCLUSIONS}

Children with FASD have a prenatal brain injury, often associated with compounding effects from postnatal deprivation and unstable social circumstances. These children require rehabilitation, special education and social support. This is accomplished by assessment and care by paediatricians, psychologists, allied health professionals and teachers, beginning in childhood and across the lifespan.

\section{Author affiliations}

${ }^{1}$ Psychiatry, Skaraborg Hospital Skövde, Skövde, Sweden

${ }^{2}$ Gillberg Neuropsychiatry Centre, University of Gothenburg, Gothenburg, Sweden

${ }^{3}$ Pediatrics, Skaraborg Hospital Mariestad, Mariestad, Sweden

${ }^{4}$ Ophthalmology, Skaraborg Hospital Skövde, Skövde, Sweden

${ }^{5}$ Clinical Neuroscience and Physiology, University of Gothenburg, Gothenburg, Sweden

${ }^{6}$ Ophthalmology, Sahlgrenska University Hospital, Mölndal, Sweden

\section{Twitter Valdemar Landgren @dahlle}

Acknowledgements We would like to thank statistician Salmir Nasic at the Skaraborg hospital research unit for sound advice.

Contributors ML, MAG, LS and EA conceptualised the study, collected data and reviewed the manuscript for important intellectual content. EG collected data, carried out initial analyses and reviewed the manuscript for important intellectual content. VL collected data, carried out initial analyses and drafted the initial manuscript. All authors have approved the final manuscript as submitted and agreed to be accountable for all aspects of the work.

Funding The study was financed by grants from Region Västra Götaland, the Swedish state under the agreement between the Swedish government and the country councils, the ALF agreement concerning research and education of doctors grants no ALFGBG-11626, ALFGBG-211671, ALFGBG-445021, ALFGBG 509761, ALFGBG 672501 and ALFGBG 71933, and the research fund at Skaraborg Hospital.

\section{Competing interests None declared.}

Patient consent for publication Not required.

Ethics approval The study was approved by the Regional Ethical Review Board, Gothenburg, and written informed consent was received from the participants.

Provenance and peer review Not commissioned; externally peer reviewed.

Data availability statement Data may be retrieved upon reasonable request to the first author.

Open access This is an open access article distributed in accordance with the Creative Commons Attribution Non Commercial (CC BY-NC 4.0) license, which permits others to distribute, remix, adapt, build upon this work non-commercially, and license their derivative works on different terms, provided the original work is properly cited, appropriate credit is given, any changes made indicated, and the use is non-commercial. See: http://creativecommons.org/licenses/by-nc/4.0/.

\section{ORCID iD}

Valdemar Landgren http://orcid.org/0000-0003-3249-8221

\section{REFERENCES}

1 Warren KR, Hewitt BG. Fetal alcohol spectrum disorders: when science, medicine, public policy, and laws collide. Dev Disabil Res Rev 2009;15:170-5.

2 Lemoine P, Harrousseau H, Borteyru JP, et al. Les enfants de parents alcooliques. anomalies observees. A propos de 127 Cas. Quest Medical 1968;25:476-82.

3 Jones K, Smith D, Ulleland C, et al. Pattern of malformation in offspring of chronic alcoholic mothers. The Lancet 1973;301:1267-71.

4 Lipinski RJ, Hammond P, O'Leary-Moore SK, et al. Ethanol-Induced face-brain dysmorphology patterns are correlative and exposurestage dependent. PLoS One 2012;7:e43067.

5 Hoyme HE, Kalberg WO, Elliott AJ, et al. Updated clinical guidelines for diagnosing fetal alcohol spectrum disorders. Pediatrics 2016;138:e20154256.
6 Coles CD, Gailey AR, Mulle JG, et al. A comparison among 5 methods for the clinical diagnosis of fetal alcohol spectrum disorders. Alcohol Clin Exp Res 2016;40:1000-9.

7 Hoyme HE, May PA, Kalberg WO, et al. A practical clinical approach to diagnosis of fetal alcohol spectrum disorders: clarification of the 1996 Institute of medicine criteria. Pediatrics 2005;115:39-47.

8 May PA, Chambers CD, Kalberg WO, et al. Prevalence of fetal alcohol spectrum disorders in 4 us communities. JAMA 2018;319:474-82.

9 Popova S, Lange S, Probst C, et al. Estimation of national, regional, and global prevalence of alcohol use during pregnancy and fetal alcohol syndrome: a systematic review and meta-analysis. Lancet Glob Health 2017;5:e290-9.

10 McQuire C, Mukherjee R, Hurt L, et al. Screening prevalence of fetal alcohol spectrum disorders in a region of the United Kingdom: a population-based birth-cohort study. Prev Med 2019;118:344-51.

11 Petković G, Barišić I. Prevalence of fetal alcohol syndrome and maternal characteristics in a sample of schoolchildren from a rural Province of Croatia. Int J Environ Res Public Health 2013;10:1547-61.

12 May PA, Fiorentino D, Coriale G, et al. Prevalence of children with severe fetal alcohol spectrum disorders in communities near Rome, Italy: new estimated rates are higher than previous estimates. Int $J$ Environ Res Public Health 2011;8:2331-51.

13 Nutt DJ, King LA, Phillips LD. Drug harms in the UK: a multicriteria decision analysis. The Lancet 2010;376:1558-65.

14 Griswold MG, Fullman N, Hawley C, et al. Alcohol use and burden for 195 countries and territories, 1990-2016: a systematic analysis for the global burden of disease study 2016. The Lancet 2018;392:1015-35.

15 Greenmyer JR, Klug MG, Kambeitz C, et al. A multicountry updated assessment of the economic impact of fetal alcohol spectrum disorder: costs for children and adults. J Addict Med 2018;12:466-73.

16 Moore EM, Riley EP. What happens when children with fetal alcohol spectrum disorders become adults? Curr Dev Disord Rep 2015;2:219-27.

17 Streissguth AP, Aase JM, Clarren SK, et al. Fetal alcohol syndrome in adolescents and adults. JAMA 1991;265:1961-7.

18 Streissguth AP, Bookstein FL, Barr HM, et al. Risk factors for adverse life outcomes in fetal alcohol syndrome and fetal alcohol effects. $J$ Dev Behav Pediatr 2004;25:228-38.

19 Chasnoff IJ, Wells AM, King L. Misdiagnosis and missed diagnoses in foster and adopted children with prenatal alcohol exposure. Pediatrics 2015;135:264-70.

20 Triseliotis J. Long-Term foster care or adoption? the evidence examined. Child Fam Soc Work 2002;7:23-33.

21 Nelson CA, Zeanah $\mathrm{CH}$, Fox NA, et al. Cognitive recovery in socially deprived young children: the Bucharest early intervention project. Science 2007;318:1937-40.

22 Landgren M, Andersson Grönlund M, Elfstrand P-O, et al. Health before and after adoption from eastern Europe. Acta Paediatr 2006;95:720-5

23 Landgren M, Svensson L, Strömland K, et al. Prenatal alcohol exposure and neurodevelopmental disorders in children adopted from eastern Europe. Pediatrics 2010;125:e1178-85.

24 Grönlund MA, Aring E, Hellström A, et al. Visual and ocular findings in children adopted from eastern Europe. Br J Ophthalmol 2004;88:1362-7.

25 Andersson Grönlund M, Landgren M, Strömland K, et al. Relationships between Ophthalmological and neuropaediatric findings in children adopted from eastern Europe. Acta Ophthalmol 2010;88:227-34.

26 Miller LC, Chan W, Litvinova A, et al. Medical diagnoses and growth of children residing in Russian orphanages. Acta Paediatr 2007;96:1765-9.

27 National High Blood Pressure Education Program Working Group on High Blood Pressure in Children and Adolescents. The fourth report on the diagnosis, evaluation, and treatment of high blood pressure in children and adolescents. Pediatrics 2004;114:555-76.

28 FAS Diagnostic and Prevention Network, University of Washington, Seattle, Washington. Diagnostic guide for fetal alcohol spectrum disorders the 4-digit diagnostic code. third edition, 2004.

29 Sheehan D, Lecrubier Y. M.I.N.I. 6.0.0. Swedish version, 2009.

30 Kessler RC, Adler L, Ames M, et al. The world Health organization adult ADHD self-report scale (ASRS): a short screening scale for use in the general population. Psychol Med 2005;35:245-56.

31 Barkley RA, Fischer M, Smallish L, et al. The persistence of attentiondeficit/hyperactivity disorder into young adulthood as a function of reporting source and definition of disorder. J Abnorm Psychol 2002;111:279-89. 
32 Busner J, Targum SD. The clinical global impressions scale: applying a research tool in clinical practice. Psychiatry 2007;4:28-37.

33 Roid G, Miller L. Leiter international performance Scale-Revised. Wood Dale IL Stoelting 1997.

34 Harrisson PL, Oakland T. Adaptive Behavior Assessment System Second, 2003

35 Spohr H-L, Willms J, Steinhausen H-C. Fetal alcohol spectrum disorders in young adulthood. J Pediatr 2007;150:175-9.

36 Rangmar J, Hjern A, Vinnerljung B, et al. Psychosocial outcomes of fetal alcohol syndrome in adulthood. Pediatrics 2015;135:e52-8.

37 Hannigan JH, Chiodo LM, Sokol RJ, et al. A 14-year retrospective maternal report of alcohol consumption in pregnancy predicts pregnancy and teen outcomes. Alcohol 2010;44:583-94.

38 Sweden S, Report A. Born in the 1970s and adopted - a look at their situation, 2014. Available: https://www.scb.se/Statistik/ Publikationer/AA9998_2014A01_BR_A40BR1404.pdf [Accessed 11 Dec 2018].

39 Streissguth AP. Understanding the occurrence of secondary disabilities in clients with fetal alcohol syndrome (Fas) and fetal alcohol effects (Fae). Available: http://lib.adai.uw.edu/pubs/bk2698. pdf [Accessed 15 Nov 2018].

40 Statistik Om övervikt och fetma - Folkhälsomyndigheten. Available: http://www.folkhalsomyndigheten.se/folkhalsorapportering-statistik/ folkhalsans-utveckling/levnadsvanor/overvikt-och-fetma/ [Accessed 10 Dec 2018].

41 Gillberg C. The essence in child psychiatry: early symptomatic syndromes eliciting neurodevelopmental clinical examinations. Res Dev Disabil 2010;31:1543-51.

42 Lindblad U, Ek J, Eckner J, et al. Prevalence, awareness, treatment, and control of hypertension: rule of thirds in the Skaraborg project. Scand J Prim Health Care 2012;30:88-94.

43 Almond D, Currie J. Killing me softly: the fetal origins hypothesis. $J$ Econ Perspect 2011;25:153-72.

44 Luu TM, Katz SL, Leeson P, et al. Preterm birth: risk factor for earlyonset chronic diseases. Can Med Assoc J 2016;188:736-46.

45 Patra J, Bakker R, Irving $\mathrm{H}$, et al. Dose-response relationship between alcohol consumption before and during pregnancy and the risks of low birthweight, preterm birth and small for gestational age (SGA)-a systematic review and meta-analyses. BJOG Int J Obstet Gynaecol 2011;118:1411-21.

46 Macleod S, Appleton RE. Neurological disorders presenting mainly in adolescence. Arch Dis Child 2007:92:170-5.

47 Connor PD, Sampson PD, Streissguth AP, et al. Effects of prenatal alcohol exposure on fine motor coordination and balance: a study of two adult samples. Neuropsychologia 2006;44:744-51.

48 Schiffman J, Sorensen HJ, Maeda J, et al. Childhood motor coordination and adult schizophrenia spectrum disorders. AJP 2009;166:1041-7.

49 Wentz E, Gillberg IC, Anckarsäter H, et al. Adolescent-Onset anorexia nervosa: 18-year outcome. Br J Psychiatry 2009;194:168-74.

50 Donald KA, Eastman E, Howells FM, et al. Neuroimaging effects of prenatal alcohol exposure on the developing human brain: a magnetic resonance imaging review. Acta Neuropsychiatr 2015;27:251-69.

51 Brown-Lum M, Zwicker JG. Brain imaging increases our understanding of developmental coordination disorder: a review of literature and future directions. Curr Dev Disord Rep 2015;2:131-40.
52 Kyllerman M, Aronson M, Sabel K-G, et al. Children of alcoholic mothers: growth and motor performance compared to matched controls. Acta Paediatr 1985;74:20-6.

53 A report: the definition and classification of cerebral palsy April 2006. Dev Med Child Neurol 2007;49:8-14.

54 Andersson Grönlund M, Dahlgren J, Aring E, et al. Ophthalmological findings in children and adolescents with Silver-Russell syndrome. $\mathrm{Br}$ $J$ Ophthalmol 2011;95:637-41.

55 Moore ES, Ward RE, Wetherill LF, et al. Unique facial features distinguish fetal alcohol syndrome patients and controls in diverse ethnic populations. Alcoholism Clin Exp Res 2007;31:1707-13.

56 Jones KL, Hoyme HE, Robinson LK, et al. Developmental pathogenesis of short palpebral fissure length in children with fetal alcohol syndrome. Birth Defects Research Part A: Clinical and Molecular Teratology 2009;85:695-9.

57 Parnell SE, Dehart DB, Wills TA, et al. Maternal oral intake mouse model for fetal alcohol spectrum disorders: ocular defects as a measure of effect. Alcoholism Clin Exp Res 2006;30:1791-8.

58 Eckhoff C, Straume B, Kvernmo S. Multisite musculoskeletal pain in adolescence and later mental health disorders: a population-based registry study of Norwegian youth: the NAAHS cohort study. BMJ Open 2017;7:e012035.

59 Menke A. Precision pharmacotherapy: psychiatry's future direction in preventing, diagnosing, and treating mental disorders. Pharmacogenomics Pers Med 2018;11:211-22.

60 Turner S, Mota N, Bolton J, et al. Self-Medication with alcohol or drugs for mood and anxiety disorders: a narrative review of the epidemiological literature. Depress Anxiety 2018;35:851-60.

61 Löser H, Bierstedt T, Blum A. [Fetal alcohol syndrome in adulthood. A long-term study]. Dtsch Med Wochenschr 1999;24:412-8.

62 Kable JA, O'Connor MJ, Olson HC, et al. Neurobehavioral disorder associated with prenatal alcohol exposure (ND-PAE): proposed DSM5 diagnosis. Child Psychiatry Hum Dev 2016;47:335-46.

63 Famy C, Streissguth AP, Unis AS. Mental illness in adults with fetal alcohol syndrome or fetal alcohol effects. Am J Psychiatry 1998:155:552-4.

64 Mukherjee RAS, Cook PA, Norgate SH, et al. Neurodevelopmental outcomes in individuals with fetal alcohol spectrum disorder (FASD) with and without exposure to neglect: clinical cohort data from a national FASD diagnostic clinic. Alcohol 2019;76:23-8.

65 Dinkler L, Lundström S, Gajwani R, et al. Maltreatment-associated neurodevelopmental disorders: a co-twin control analysis. J Child Psychol Psychiatr 2017;58:691-701.

66 Sonuga-Barke EJS, Kennedy M, Kumsta R, et al. Child-to-adult neurodevelopmental and mental health trajectories after early life deprivation: the young adult follow-up of the longitudinal English and Romanian adoptees study. The Lancet 2017;389:1539-48.

67 Aronson M, Hagberg B, Gillberg C. Attention deficits and autistic spectrum problems in children exposed to alcohol during gestation: a follow-up study. Dev Med Child Neurol 1997;39:583-7.

68 Mukherjee R, Layton M, Yacoub E, et al. Autism and autistic traits in people exposed to heavy prenatal alcohol: data from a clinical series of 21 individuals and nested case control study. Adv Ment Health Intellect Disabil 2011;5:42-9.

69 Clark DL, Boutros NN, Mendez MF. The brain and behavior: an introduction to behavioral neuroanatomy. Leiden: Cambridge University Press, 2010. 